\title{
Plataforma digital de fuentes para la historia económica mexicana
}

\author{
María J. Ramirez Magallón*
}

A principios de 2014 me inscribí para formar parte del directorio de historiadores económicos que estuvo impulsando la Asociación Mexicana de Historia Económica (AMHE). Vi con simpatía los temas que trabajan los investigadores afiliados, ya que comparto el interés por muchos de ellos y además, son referentes obligatorios para mis trabajos de investigación. Al ser la única profesora cercana a Colima que forma parte de dicho directorio, fui invitada a integrarme a un grupo de corresponsales que debían fomentar los trabajos que la AMHE tiene como razón social.

Entre las dificultades que enfrenta un historiador en formación están la falta de recursos humanos y materiales para impulsar el trabajo, como en Colima, en donde no existe una licenciatura en Historia y el Cuerpo Académico universitario es pequeño. La consigna en ese momento fue cumplir con mi compromiso y buscar a los amigos locales y regionales que estuvieran interesados en preservar fuentes históricas, en difundir las investigaciones de los colegas de sus estados y en fomentar la investigación histórica.

Al llamado acudieron profesores de la Facultad de Historia de la Universidad Michoacana, investigadores de la Universidad de Guadalajara, compañeros del Doctorado en Historia de El Colegio de Michoacán y colegas de varios estados mexicanos. Nuestros anfitriones fueron el Archivo Histórico de la Universidad de Colima y la Sociedad Colimense de Estudios Históricos. El objetivo en ese momento era conocer a quienes estaban desarrollando alguna investigación histórica de corte económico, a quienes trabajan con los repositorios regionales y a los historiadores en formación.

Entre las pláticas de 2015, cuando realizamos nuestras Jornadas en Colima, salió el tema de construir plataformas en donde compartamos información acerca de las fuentes históricas y repositorios que todos usamos. Este es un esfuerzo necesario porque la mayoría de nosotros recibimos financiamiento 
público para nuestras investigaciones, de manera que los apuntes, bases de datos e instrumentos que podemos facilitar a los propios Archivos y a los investigadores, contribuye con la preservación de documentos que están a punto de desaparecer.

En 2016, el doctor Carlos Marichal nos habló del Boletín de Fuentes para la Historia Económica de México, del cual fue editor en El Colegio de México, en la década de 1990. Habló acerca de la necesidad de que nuevas generaciones de historiadores se involucraran en los trabajos que han quedado inconclusos. Como corresponsal de la AMHE en los estados de Colima y Michoacán, le planteamos el proyecto a la doctora Sandra Kuntz, entonces presidenta de la AMHE, quien nos dio el visto bueno para arrancar.

Nuestra idea, ya en coordinación con un grupo de amigos y colegas, era editar los materiales que se publicaron desde El Colegio de México. La aportación de mis compañeros de generación y de otros colegas con quienes he trabajado desde 2011 en iniciativas similares, sería la construcción de una plataforma sencilla, amigable y práctica, a través de la cual los usuarios podrán acceder a los ensayos referidos, ubicar espacialmente los repositorios que cada investigador refiere, añadir los archivos históricos, públicos o privados, que cuenten con documentos para el quehacer del historiador económico.

La construcción de esta plataforma contó con el apoyo de los doctores Martín Sánchez Rodríguez y José Antonio Serrano; el primero de ellos es investigador en el Centro de Estudios Históricos y el segundo, investigador y Presidente de El Colegio actualmente. Tras obtener el respaldo de nuestros profesores nos reunimos para editar los artículos que fueron publicados en el Boletín de El Colegio de México, posteriormente geolocalizamos los Archivos Históricos a los cuales nos remiten esos documentos, completamos los datos editoriales, escribimos breves resúmenes y ordenamos la información para que un técnico de El Colegio de Michoacán nos ayudara a construir la página web que ideamos para el proyecto.

El objetivo de esta plataforma, al igual que el del Boletín original, es "actualizar la información de los archivos consultados en los años recientes por los estudiosos de la historia económica de México. Va dirigida a estudiantes e investigadores y tiene que ver con los intereses que han manifestado particulares, instituciones y empresas por dar a conocer sus fondos archivísticos y bibliográficos que son poco conocidos. En [la] primera versión de la Guía se dan a conocer alrededor de cien fondos o grupos documentales ubicados en México y el extranjero. Asimismo, pretendemos dar a conocer las experiencias adquiridas por historiadores consolidados y por nuevos historiadores que se han acercado a dichas fuentes". ${ }^{1}$

1 Carlos Marichal, Guía de Fuentes para la Historia Económica de México, en ColmichSig, 2017. 
Los antecedentes de este proyecto, como bien lo dice el doctor Carlos Marichal, son diversos y variados. En principio retoma y destaca la labor de importantes historiadores e instituciones educativas que en el siglo $\mathrm{XX}$ publicaron "una gran cantidad de obras que contenían documentos inéditos" sobre la historia económica mexicana. ${ }^{2}$

Durante el año 2017 hemos trabajado con Marco Hernández, técnico de El Colegio de Michoacán, quien se ha especializado en Sistemas de Información Geográficos (SIG), para construir y alimentar la plataforma. Nuestro demo fue presentado en la Mesa de Fuentes para la Historia Económica de México, organizada por el doctor Carlos Marichal en el marco de las II Jornadas de Historia Económica del Occidente de México, realizadas en El Colegio de Michoacán en septiembre de 2017.

La navegación es sencilla: una vez que el usuario accede al Repositorio de SIG de El Colegio de Michoacán puede navegar en nuestro espacio (titulado provisionalmente como Boletín para la Historia Económica Beta 1.2), el cual está organizado de la siguiente forma:

1) Banca

2) Comercio

3) Empresarios

4) Fiscalidad

5) Haciendas

6) Iglesia

7) Industria

8) Infraestructura

9) Minería

10) Ventanas al mundo

Por sugerencia de Marco Hernández, agregamos una sección para que los usuarios envíen sus propuestas de colaboración, consistentes en ensayos, instrumentos de consulta o información inédita y de su autoría. Para ello prepararemos un instructivo que servirá para que los usuarios colaboren sin mayores dificultades.

Nuestro equipo quiso añadir una sección de Archivos regionales y nacionales, tanto públicos como privados, que contienen información valiosa para el estudio de la historia mexicana. Esta idea surgió porque algunos ensayos nos remiten a más de un Archivo Histórico local, estatal o nacional y si asociamos todos ellos a un mismo documento, la navegación en la Plataforma podría ser confusa. Por esta razón, recurrimos a colegas de diversas entidades federativas y de otras regiones con la finalidad de completar las listas de repositorios que ellos conocen; de tal suerte que hemos compilado una lista

2 Carlos Marichal, Guía de Fuentes, 2017. 
con Archivos Históricos del Continente americano, comenzando con Filipinas, por su importancia en la historia colonial mexicana y sumando los Archivos nacionales de Las Antillas, los principales Archivos históricos europeos y aquellos Archivos Privados o eclesiásticos que hemos podido geolocalizar.

Esperamos que la Plataforma esté en perfecto funcionamiento a mediados de 2018, tanto en la versión castellana como en la inglesa y que este esfuerzo colectivo sea una muestra de las posibilidades creativas y constructivas que los historiadores tenemos con las fuentes y con la disciplina. Así mismo, sirva como ejemplo para mostrar que el proyecto de corresponsalías impulsado por la AMHE tiene mucho que ofrecer al gremio de historiadores del mundo. 